\title{
Imaginarios sociopolíticos de los jóvenes indígenas en la ciudad de Bogotá*
}

\section{Social and Political Imaginary Indigenous Youth in Bogota City}

\section{Cristhian J. Uribe Mendoza}

Referencia para citar este artículo: URIBE MENDOZA., C. J. (2013). "Imaginarios sociopolíticos de los jóvenes indígenas en la ciudad de Bogotá". En Revista Guillermo de Ockham 11(2). pp. 53-67.

\section{Resumen}

El presente artículo tiene como objetivo analizar los imaginarios sociopolíticos de un grupo de jóvenes pertenecientes a diferentes comunidades indígenas que residen en la ciudad de Bogotá, Colombia. Concretamente, se reflexiona en torno a los siguientes elementos: la condición juvenil dentro de la población indígena, la percepción de sus jóvenes frente a la ciudad y a la forma como allí se desarrolla su identidad cultural y, finalmente, las significaciones que estos sujetos han construido en relación con la política. Los resultados sugieren que los jóvenes indígenas recrean nuevas imágenes y significaciones con respecto al imaginario socialmente instituido de juventud, ciudad y política, a partir de sus vivencias, percepciones, expectativas y particularidades culturales y generacionales.
Palabras clave: imaginarios, jóvenes, indígenas, Bogotá, política.

\section{Abstract}

This paper aims at analyzing the sociopolitical imaginaries of a group of young people coming from different indigenous communities residing in the city of Bogotá, Colombia. Specifically, it reflects on the following: the youth condition within the indigenous population, the perception of ethnic youth vis-à-vis the city and the way their cultural identity is developed there and, finally, the meanings that these individuals have constructed in relation to politics. The results suggest that indigenous youth recreates new images and meanings as to socially instituted imaginaries on youth, the city and politics, based on their experiences, perceptions, expectations and generational and cultural peculiarities.

CRISTHIAN J. URIBE MENDOZA. Sociólogo de la Universidad Nacional de Colombia. Estudiante de la Maestría en Ciencia Política de la Universidad de los Andes. Investigador del Observatorio de Juventud y del Grupo de Estudios Políticos y Sociales (Theseus) de la Universidad Nacional de Colombia. Correo electrónico: cjuribem@unal.edu.co.

\footnotetext{
* Este artículo de investigación científica y tecnológica es producto del proyecto "Imaginarios sociopolíticos de los jóvenes indígenas en la ciudad de Bogotá", financiado por Colciencias en convenio especial de cooperación (No. 0043-2012) con la Universidad Nacional de Colombia, programa Jóvenes Investigadores e Innovadores "Virginia Gutiérrez de Pineda" (convocatoria 525 de 2011), el Observatorio de Juventud y el Grupo de Estudios Políticos y Sociales (Theseus) de la misma universidad. Tutor: profesor Fabián Rodolfo Acosta. Fecha de inicio: 15 de junio de 2012. Fecha de culminación: 18 de junio de 2013.
} 
Keywords: imaginaries, indigenous, youth, Bogotá, politics.

\section{Introducción}

La pregunta por la condición juvenil dentro de las comunidades indígenas en América Latina adquirió mayor importancia debido a los cambios sociales, políticos, económicos y culturales ocurridos en la región a finales del siglo XX. De acuerdo con Feixa y González (2006), antes de dicho periodo, los estudios socioculturales no tuvieron en cuenta los jóvenes indígenas dentro de sus análisis, pues consideraban que "los individuos pertenecientes a las clases y culturas subalternas se incorporaban tempranamente a la vida adulta, tanto en términos laborales como sexuales" ( $\mathrm{p}$. 172). En consecuencia, gran parte de los trabajos académicos ignoraron, por un lado, las alteridades culturales coexistentes en Latinoamérica y por otro, la existencia de una etapa social equivalente a la concepción occidental de juventud dentro de las comunidades indígenas y rurales.

En contraposición, estudios recientes han comenzado a abordar la cuestión de la condición juvenil indígena desde múltiples enfoques teóricos y metodológicos. Entre las temáticas que más han llamado la atención de los investigadores, se encuentran: el surgimiento de la condición juvenil indígena (Castro Pozo, 2008a; Unda Lara et al., 2011 y Zapata et al., 2005, entre otros); la migración de los jóvenes de origen étnico hacia los centros urbanos (Aravena, 2012; Rokael Cardona, 1999; Castro Pozo, 2008b; Del Popolo et al., 2011; y Falla, 2008, entre otros); y la experiencia de los jóvenes indígenas universitarios (Gallart Nocetti et al., 2006; Mayorga, 2008; y Ortelli et al., 2011, entre otros).

Sin embargo, pocos estudios teóricos y empíricos sobre juventud indígena se han detenido a examinar los imaginarios que estos hombres y mujeres han construido frente a diferentes ámbitos de su vida personal y social. Identificar tales imaginarios resulta fundamental para comprender la forma como los jóvenes indígenas perciben, explican, intervienen y re-significan la realidad actual a partir de sus vivencias cotidianas y de su identidad étnica.

Así pues, este artículo presenta los resultados de la investigación Imaginarios sociopolíticos de los jóvenes indigenas en la ciudad de Bogotá, que busca caracterizar el imaginario que un grupo de jóvenes de origen étnico ha construido en torno a lo que significa "ser joven", sus percepciones frente a la ciudad y a la forma como en ella se desarrolla su identidad cultural y, finalmente, las significaciones que estos sujetos han construido en relación con la política.

\section{Diseño metodológico de la investigación}

Este estudio se enmarca dentro de la perspectiva cualitativa-interpretativa de investigación social que permite comprender e interpretar la realidad a partir de las percepciones, experiencias, interacciones o vivencias cotidianas del grupo de sujetos implicados en el objeto de estudio; que en nuestro caso, es el imaginario sociopolítico de los jóvenes pertenecientes a diferentes cabildos ${ }^{1}$ y pueblos indígenas que residen en la ciudad de Bogotá ${ }^{2}$.

De acuerdo con Agudelo (2011), la única manera de acceder a los imaginarios es a través de su materialización semiótica; es decir, mediante los discursos, textos y acciones narrativas de los sujetos. En consecuencia, se emplearon dos técnicas para la recolección de la información: la entrevista semiestructurada y el grupo focal. Estas dos técnicas permitieron reconstruir la realidad socioimaginaria de los jóvenes indígenas que participaron en esta investigación, a partir del relato de sus experiencias personales y de la búsqueda de significados y puntos

1. Según el artículo 2o. del Decreto 2001 de 1988, un cabildo es "una entidad pública de carácter especial, cuyos miembros son indígenas elegidos y reconocidos por una parcialidad localizada en un territorio determinado, encargado de representar legalmente a su grupo y ejercer las funciones que le atribuye la ley y sus usos y costumbres. Los cabildantes deben ser miembros de la comunidad que los elige y la elección se hará conforme a lo dispuesto en la Ley 89 de 1890 o por sus propias formas de organización tradicional".

2. En Bogotá se ha identificado la presencia de aproximadamente cuarenta y dos comunidades indígenas. Entre estas, en la actualidad, solo cinco se encuentran registradas y reconocidas legalmente bajo la figura de cabildo, a saber, Cabildo Indígena Muisca de Suba, Cabildo Indígena Muisca de Bosa, Cabildo Indígena Inga, Cabildo Indígena Ambiká Pijao y Cabildo Indígena Kichwa. Sin embargo, la ciudad registra otros procesos organizativos de pueblos étnicos que buscan ser reconocidos como cabildo. Estos son: el pueblo nasa, el pueblo yanacona, el pueblo pastos, el pueblo misak misak y el pueblo uitoto, entre otros (Política Pública Distrital para el reconocimiento, garantía, protección y restablecimiento de derechos de los pueblos indígenas, 2011). 
de vista compartidos en torno a algunas variables de interés, tales como juventud indígena, ciudad, conflictos identitarios y política.

Así las cosas, en un primer momento se hizo una entrevista semiestructurada con el fin de examinar la trayectoria social, las vivencias y las percepciones de nuestros informantes con respecto a las variables de interés. La muestra fue seleccionada siguiendo el criterio de heterogeneidad que busca captar la mayor variedad de experiencias posibles en cuanto a origen étnico, edad, sexo y ocupación, etc. De este modo, se entrevistaron individualmente seis hombres y cinco mujeres, con un rango de edad entre diecinueve y treinta ańos, pertenecientes a los siguientes pueblos indígenas: arhuaco, inga, kichwa, muisca, nasa y pastos. Entre los entrevistados había estudiantes universitarios, profesionales, empleados públicos y trabajadores independientes. Cinco de ellos nacieron en Bogotá y los seis restantes provienen de diferentes zonas del país como los departamentos de Cauca, Huila y Santander y la Sierra Nevada de Santa Marta.

En un segundo momento, se configuró un grupo focal que sirvió para discutir y ubicar algunos puntos de convergencia en relación con la temática planteada. Este espacio estuvo centrado en la reconstrucción de imaginarios de los jóvenes indígenas urbanos a partir de las significaciones y experiencias identificadas durante la aplicación de la entrevista. En este grupo focal, participaron dos hombres y tres mujeres, con un rango de edad comprendido entre los diecinueve y los veintiocho años y pertenecientes a los pueblos indígenas kichwa, muisca, nasa y pastos.

Para analizar la información recolectada en las entrevistas y en el grupo focal, se diseñó una matriz que codificaba y relacionaba las respuestas de los informantes con las preguntas y variables de interés, de tal manera que fuera posible establecer parámetros de comparación entre ellas. Finalmente, se organizó una reunión con cinco jóvenes que participaron en esta investigación con el fin de socializar, retroalimentar y validar los resultados.

\section{El enfoque de los imaginarios sociales}

En términos amplios, los imaginarios sociales son "aquellos esquemas construidos socialmente que nos permiten percibir algo como real, explicarlo e intervenir operativamente en lo que en cada sistema social se considere como realidad" (Pintos, 2001, p.14). Si bien tales representaciones afectan los modos de sentir, pensar y actuar de los individuos, ellos se configuran a partir de ciertos procesos de socialización en el marco de condiciones sociohistóricas determinadas. En consecuencia, Castoriadis (1989) afirma que "la institución de la sociedad es en cada momento institución de un magma de significaciones imaginarias sociales, que podemos y debemos llamar mundo de significaciones" (p. 312). Ese mundo de significaciones colectivas se "encarna" en las instituciones y, como tal, condiciona las creencias, pensamientos y comportamientos de los miembros de la sociedad. Adicionalmente, tal como lo señala Fressard (2006), Castoriadis sostiene que toda sociedad siempre es histórica y siempre atraviesa un proceso de alteración; por lo cual, "siempre existe un doble modo: el modo de 'lo instituido', estabilización relativa de un conjunto de instituciones, y el modo de 'lo instituyente', la dinámica que impulsa su transformación" (Fressard, 2006, p.58).

Con base en lo anterior, se pueden distinguir dos tipos de imaginarios: el imaginario social instituido y el imaginario social instituyente. El imaginario instituido se refiere al conjunto de representaciones simbólicas, significaciones y condiciones preestablecidas que estructuran las expectativas, las conductas, las metas y las posibilidades de los individuos en el mundo social. Por otra parte, el imaginario social instituyente alude al cambio, a la posibilidad de surgimiento de nuevas significaciones imaginarias: "este es el opositor al status quo caracterizado por proponer diversas concepciones del mundo, de la vida y del orden” (Guzmán Rocha, 2005, p. 73).

De igual manera, Castoriadis (1989) propone otro concepto de gran utilidad para nuestro estudio, a saber, el de imaginación radical. La imaginación radical se relaciona con el imaginario social instituyente en que ambos conceptos se refieren a la facultad de crear nuevas significaciones sobre la realidad actual; no obstante, el autor sitúa la potencia de la imaginación radical en el plano de psique, de lo individual y en esa medida el sujeto con imaginación radical es un "sujeto que se asume como alteridad y como origen perpetuo de alte- 
ridad" (Hurtado, 2007, p. 221), un sujeto capaz de producir nuevas imágenes y significaciones.

En este orden de ideas, los sujetos también se encuentran inmersos en la tensión entre lo instituido y lo instituyente, dos campos de fuerza indisociables (debido a que lo instituido no puede ser pensado por fuera de lo instituyente), pero que están en pugna permanentemente dentro de un mismo sistema social. Por lo tanto, cuando el sujeto se aproxima al modo de lo instituido "toma la forma de sujeto-agente funcional del sistema"; en cambio, cuando se aproxima al modo de lo instituyente, "aparece como sujeto activo, creativo, productor y creador” (Cubides Martínez, 2011).

En síntesis, el enfoque de los imaginarios sociales no solo permite comprender el proceso mediante el cual los seres humanos perciben, instituyen y transforman la realidad en un tiempo y en un sistema social determinados, sino que también resulta útil para identificar los referentes que orientan y condicionan las prácticas cotidianas de los individuos y colectividades. Los deseos, las creencias, las identidades, los valores y las costumbres, expresados a través de discursos, representaciones y acciones, reflejan el imaginario que los sujetos tienen de sí mismos y del otro (etnia, grupo, comunidad, etc.) (Agudelo, 2011).

\section{La construcción social de la juventud}

Los jóvenes, desde el momento de su aparición en el mundo social, llamaron la atención de expertos provenientes de diferentes disciplinas de las ciencias sociales que se aproximaron a ellos con "voluntad de saber", es decir, con la pretensión de conocer sus actuaciones, experiencias, preocupaciones, anhelos, etc. Así pues, se configuraron múltiples discursos acerca de su existencia, legitimidad y reconocimiento social (situación que no se presentó por igual o en absoluto en todos los países, culturas o clases sociales).

La categoría juventud hace imprescindible una mirada histórica que resalte las variaciones que ha sufrido esta categoría dependiendo de las contingencias sociales y culturales, como también las diferentes formas en que los sistemas expertos han determinando el itinerario desde el cual asumirla (Hurtado, 2007, p. 30).
De acuerdo con Hurtado (2007), el surgimiento de la categoría juventud se asocia con una serie de transformaciones que experimentaron las instituciones sociales (familia, escuela, ejército, etc.) a partir de la segunda revolución industrial. Bajo este contexto, el sistema productivo se dotó de avances tecnológicos que exigían una mayor preparación por parte de quienes se incorporarían al mercado laboral. De este modo, surgió la idea de moratoria social, un periodo en el cual los individuos -tras haber superado la etapa de la niñez- postergan la adopción plena de responsabilidades económicas y familiares con el fin de acceder a una institución educativa y preparase para el "mundo adulto". Si bien la moratoria social no explica completamente lo que la juventud representa como fenómeno social -pues dicha moratoria constituye una característica reservada para aquellos sectores sociales con mayor capital económico y cultural-, sí resulta fundamental a la hora de definir lo que hace posible la juventud como configuración social significativa (Acosta, Galindo Ramírez, y Cubides, 2011). En consecuencia, el ingreso masivo de jóvenes y adolescentes a la instrucción pública a mediados del siglo XIX creó las condiciones para el surgimiento de la juventud como grupo social significativo. No obstante, cabe aclarar que esta inserción de los jóvenes dentro de la estructura social conlleva grandes diferencias y desigualdades de sexo, generación y clase social, lo que afecta de manera diversa sus esquemas de percepción del mundo (Arango Gaviria, 2006).

Ahora bien, entre los múltiples imaginarios que se han construido alrededor de la categoría juventud, cabe destacar los siguientes: la juventud como categoría etaria, que asigna a esta población cierto margen de edad, objetivable y determinada por unos rasgos psicobiológicos particulares; la juventud como etapa de preparación, que se refiere al joven como un individuo incompleto o inmaduro, que carece de preparación para asumir responsabilidades propias de la vida adulta (ingreso al mundo laboral, conformación de una familia, autonomía, etc.); la juventud como problema social, que concibe a los jóvenes como los causantes directos de la violencia urbana y, por ende, un grupo que debe ser controlado y mantenido en permanente observación; la juventud como agente de cambio social, que le asigna a esta población un papel preponderante en la transformación de la sociedad; y la juventud 
hedonista anclada a la sociedad de consumo y a la búsqueda de placer (sexo, drogas, música, etc.). Desde esta última perspectiva, la juventud "encarnó los nuevos ideales de belleza y de consumo y constituyó uno de los principales objetivos de las nuevas industrias culturales y de las tecnologías de recreación" (ibíd, p. 313).

Por otra parte, comprender la juventud como una construcción social tiene varias implicaciones: primero, implica que la juventud no existe como un estado naturalmente dado; en otras palabras, su existencia está determinada de modo relativo por las características, significados y funciones atribuidos por la sociedad. Segundo, implica que no existe una única juventud, sino múltiples significados, experiencias, identidades y expresiones en torno a la condición juvenil. Tercero, comporta que la juventud posee un carácter histórico y, por lo tanto, se encuentra condicionada espacio-temporalmente (Galindo Ramírez, 2012). Así pues, conviene concebir la juventud como una construcción social, heterogénea y contingente.

Finalmente, aunque la juventud es una construcción social, resulta apropiado reconocer a los jóvenes como sujetos de la imaginación radical, es decir, como individuos capaces de producir sus propias representaciones, deseos y afectos (Hurtado, 2007); en esa medida, los sujetos jóvenes tienen la posibilidad de resignificar de manera individual y colectiva lo que involucra ser joven y lo que está por fuera del mundo juvenil a partir de sus vivencias, percepciones y expectativas.

\section{La condición juvenil indígena}

Uno de los factores que ha posibilitado el surgimiento de la condición étnico-juvenil es el acceso de personas indígenas a la educación secundaria y universitaria. La escuela, la introducción de la telesecundaria y los convenios de admisión especial de indígenas en instituciones de educación superior, han permitido la visibilidad y el reconocimiento de los jóvenes de origen étnico como grupo social significativo. Dicho reconocimiento implica la configuración de una especie de "moratoria social" en la que los jóvenes indígenas postergan sus responsabilidades económicas, familiares y sociales con el fin de dedicarse a actividades propias de la educación formal. Asimismo, las instituciones educativas se han configurado como un escenario no solo donde se adquieren nuevos saberes, sino también donde se desarrollan estilos juveniles particulares:

La telesecundaria no solo representa un centro para estudiar y prepararse, sino un espacio donde los jóvenes adquieren un estilo y un status, al pasar un tiempo de su vida compartiendo espacios, juegos, ocio, alegrías, tristezas y muchas otras situaciones que los articulan como subgrupos dentro de la comunidad (Castro Pozo, 2008, p. 11).

Por otra parte, la adopción del sistema educativo occidental ha generado tensiones dentro de las comunidades, puesto que en él los jóvenes indígenas adquieren conocimientos y construyen expectativas de vida que muchas veces entran en conflicto con los conocimientos y valores tradicionales de su pueblo. Por esta razón, diversas comunidades han fundado jardines infantiles, escuelas e incluso universidades en las cuales se imparte una educación alternativa basada en sus propias necesidades, intereses y cosmovisiones.

Otro de los factores determinantes en el proceso de construcción de la condición juvenil indígena es la migración. Según Cardona (1999), la migración indígena hacia los centros urbanos obedece a causas estructurales vinculadas con la proletarización del campo, la pobreza rural y el crecimiento demográfico, entre otras; fenómeno que se agudiza por ciertas situaciones coyunturales como el conflicto armado y la inseguridad rural. Asimismo, las migraciones urbanas afectan principalmente a los miembros más jóvenes de las comunidades, quienes deben afrontar diversas tensiones y contradicciones derivadas de su proceso de inserción a la vida social, cultural, política y económica de la ciudad, con lo cual ponen en riesgo su relación cultural con el territorio, valores $\mathrm{y}$ costumbres ancestrales.

De esta manera, los jóvenes indígenas se exponen a conflictos identitarios; esto es, a situaciones de discriminación a causa de su origen étnico (Aravena, 2009). La adaptación a la cultura urbana dominante implica para los jóvenes indígenas enfrentarse a un imaginario social instituido que, por lo general, se encuentra altamente cargado de prejuicios y rechazo hacia las minorías. En medio de este conflicto socioimaginario, el joven se ve forzado en ocasiones a negar su identidad como 
mecanismo de adaptación a la vida urbana; o, por el contrario, puede reafirmarla y dar lugar a lo que Aravena define como una "experiencia de etnicidad positiva”.

Adicionalmente, cabe mencionar que la bibliografía especializada en la materia ha propuesto otras explicaciones para el surgimiento de la juventud indígena en América Latina, entre las cuales se encuentran: 1) los procesos organizativos comunitarios mediante los cuales se reconoce al joven como un actor social que reclama espacios de participación e inclusión y como agente clave para la reproducción del modelo cultural y social de la comunidad (Zapata Cardona y Hoyos Agudelo, 2005); 2) el peso demográfico de los jóvenes dentro de la población étnica; y 3) la influencia de los medios masivos de comunicación (Del Popolo y Robotta, 2011; Castro Pozo, 2008).

Resulta importante aclarar que no existe consenso alguno frente a lo que significa ser joven indígena, pues cada comunidad construye sus propios significados y valoraciones en torno a dicha condición (Pérez Ruiz, 2008); no obstante, tal como lo seńala Pérez Ruiz (2008), hoy es comprobable que la juventud existe como segmento social diferenciado dentro de los pueblos ancestrales, muchos de los cuales cuentan con términos propios para referirse a las nuevas generaciones:

En las poblaciones en donde existe el concepto de joven en lengua propia, en general, se trata de una categoría social que marca una etapa de vida que [...] se inicia con la adquisición de ciertos rasgos biológicos -los de la pubertad- y concluye con la incorporación del joven a la vida adulta, la cual se reconoce porque es cuando el individuo asume una serie de compromisos asociados con el matrimonio, con la responsabilidad de tener y cuidar una familia y de adquirir responsabilidades sociales con la comunidad (Pérez Ruiz, 2008, p. 20).

En suma, la construcción social de la condición juvenil indígena se engloba bajo las nuevas formas de relacionamiento entre los pueblos originarios y las sociedades urbanas. Asimismo, aproximarse a la cuestión de la juventud indígena implica tener en cuenta primero, la coyuntura y problemáticas específicas que posibilitaron su aparición en el mundo social (v.gr. desempleo rural, migración, conflicto armado, etc.); segundo, los itinerarios y particularidades del periodo juvenil visto desde la perspectiva de las comunidades; y, tercero, la apropiación y resignificación del concepto de juventud occidental por parte de los jóvenes de origen étnico.

\section{La resignificación socioimaginaria de la condición juvenil indígena}

Para los participantes de esta investigación no existe una única manera ni un modo taxativamente correcto de definir la condición juvenil indígena. Por el contrario, consideran que cada individuo y cada comunidad construyen múltiples significaciones alrededor de ella con base en sus experiencias, creencias, cosmovisiones, etc. Pese a ello, se observan algunos puntos de convergencia que nos permiten caracterizar el fenómeno en cuestión.

Un primer punto de convergencia estriba en que la condición juvenil indígena no está determinada por un rango de edad específico, sino por el nivel de conocimiento que desarrollan los seres humanos a lo largo de sus vidas:

[La juventud] tiene mucho que ver con el proceso de cada persona. Por ejemplo: una persona que inicia la edad adulta tendrá primero que haber pasado por un proceso. Cada etapa de la vida [niñez, adolescencia, adultez, vejez] simboliza un nivel de aprendizaje interno, la incorporación de ciertos conocimientos que le van a permitir a los individuos acercarse a sí mismos y a su entorno de manera responsable (entrevista 2, hombre, 24 años).

$\mathrm{Al}$ corriente de esta lógica, la juventud es concebida como una etapa de aprendizaje en la que los jóvenes indígenas adquieren los conocimientos, las habilidades y las destrezas necesarias para desempeñar las responsabilidades de los adultos. Esta concepción está asociada con el imaginario de que los jóvenes son el futuro de la comunidad y por ende, las nuevas generaciones deben seguir el consejo y el ejemplo de los mayores con el fin de conservar y reproducir los valores y costumbres ancestrales.

Ahora bien, los jóvenes indígenas asumen cierto tipo de responsabilidades que varían según las condiciones particulares de cada persona. Por ejemplo, aquellos que llevan a cabo estudios técnicos o universitarios coinciden en que su principal responsabilidad es obtener el respectivo título y 
luego emplear las habilidades y conocimientos adquiridos en beneficio de su comunidad. Durante este periodo, los jóvenes suelen postergar ciertas responsabilidades, tales como la conformación y sostenimiento de una familia, la maternidad y el trabajo comunitario, entre otras, con el fin de concentrarse en el cumplimiento de sus compromisos académicos.

Nuestra responsabilidad es aprender; nosotros venimos acá a aprender, a conocer muchas cosas $\mathrm{y}$, precisamente, cuando uno sale de allá uno se compromete a regresar, a trabajar para la comunidad, para que otras personas tengan la posibilidad de estudiar (entrevista 7, hombre, 21 años).

Por su parte, los jóvenes indígenas que se dedican a trabajar relacionan la juventud con la adquisición de nuevas responsabilidades; ello debido a que su trabajo les permite obtener una mayor independencia económica y familiar. De esta manera, la condición juvenil indígena es vista como el momento en que las personas empiezan a desprenderse de sus padres para vivir nuevas experiencias, conseguir empleo, tomar decisiones autónomamente, construir un proyecto de vida, etc. Cabe aclarar que los jóvenes entrevistados mantienen un fuerte vínculo con el pueblo indígena al que pertenecen; por lo tanto, consideran que su responsabilidad es trabajar no solo para subsistir, sino también para fortalecer los procesos organizativos de la comunidad, ya sea ejerciendo algún cargo dentro del cabildo o desde fuera desarrollando proyectos a su favor.

Otro punto de convergencia radica en que el estado juvenil indígena se percibe como una etapa caracterizada por la relativa disponibilidad de tiempo para el esparcimiento, la diversión, el ocio y el deporte. Por consiguiente, tanto en el territorio de origen como en la ciudad, los hombres y mujeres jóvenes cuentan con espacios de integración donde practican sus deportes favoritos, asisten a eventos de música, comparten con amigos, se relacionan con personas del sexo opuesto, etc. Ello a su vez, permite que las juventudes adquieran una mayor visibilidad como subgrupo social significativo den- tro de sus respectivas comunidades. Asimismo, la cantidad de tiempo libre disminuye en la medida en que los van adquiriendo responsabilidades económicas, familiares y sociales:

Ser joven significa tener cierta libertad, como en pensamientos y en comportamientos; no es libertinaje, sino que cuando uno es joven tiene más energía, actitud para divertirse, para hacer cosas nuevas. [...] Después de eso uno tiene que asumir responsabilidades y ya deja de ser joven (entrevista 1 , mujer, 22 años).

Dentro del imaginario de la población indígena joven, la condición juvenil termina cuando los hombres y mujeres alcanzan la experiencia y madurez necesarias para asumir las funciones sociales de las personas mayores. De esta manera, en relación con las mujeres el tránsito de la juventud a la adultez está determinado por situaciones como dejar la casa de sus padres, tener su primer hijo, contraer matrimonio y aprender a tejer artesanías, entre otras. En lo que respecta a los hombres, dicho tránsito se caracteriza por la adquisición de responsabilidades como trabajar, mantener el hogar, aprender algún arte y oficiar rituales, entre otras. Del mismo modo, en algunas comunidades la condición juvenil indígena termina cuando se recibe el poporo ${ }^{3}$, lo que significa que el joven está preparado para acceder al grupo de los hombres aptos para la vida sexual:

Esa categoría de joven [...] termina cuando el hombre asume el poporo, es decir, su pareja espiritual, su compañera espiritual, y eso viene a ser cuando ha terminado parte del desarrollo físico; es decir, sus brazos han cambiado, ya tiene fuerza, tiene vello, puede procrear (entrevista 10, hombre, 30 años).

Cabe destacar que el imaginario de juventud de los jóvenes indígenas se ha configurado a partir de ciertos procesos de socialización llevados a cabo mediante el diálogo intergeneracional con sus padres u otras personas adultas allegadas a su núcleo familiar o comunitario; por consiguiente, no resulta extraño que aquellos reproduzcan discursivamente la idea de juventud que se ha construido y legitimado socialmente en su pueblo de origen.

3. Pueblos indígenas como los arhuacos y los muiscas, entre otros, emplean el poporo, un calabazo que tiene en su interior cal extraída de unas conchas de mar específicas para uso ritual. Esta se mezcla con saliva y hojas de coca (también conocidas como ayú) con el fin de producir una sustancia que para la población indígena constituye una herramienta espiritual que los acompańa en sus labores cotidianas y con la cual se medita y se configuran pensamientos que equilibran la vida en el territorio. El poporo es entregado a los adolescentes cuando llegan a una edad apta para iniciar su vida sexual y a partir de ahí este se convierte en su compañía espiritual por el resto de sus vidas. 
A su vez, se observa que estos jóvenes, en cuanto sujetos de la imaginación radical, resignifican el imaginario instituido de juventud atribuyéndole características derivadas de sus propias vivencias, perspectivas, particularidades y contextos, lo cual explica la dificultad para llegar a un consenso en torno al significado de la condición étnico-juvenil. Frente a esta situación, que no es otra cosa que la tensión entre lo instituido y lo instituyente, "[...] el sujeto juvenil es creado y es creador a la luz del imaginario social que le ha sido instituido, no solo por su capacidad de generación de lo nuevo, sino por la capacidad de desplazamiento de sentido" (Hurtado, 2006, p. 8).

\section{La ciudad como escenario de reafirmación de la identidad étnica}

Tal como se mencionó anteriormente, la migración de las juventudes indígenas hacia los centros urbanos ha sido determinante en la configuración de la condición juvenil dentro de la población étnica. No obstante, se debe tener en cuenta que muchos de los jóvenes de origen étnico que residen en la ciudad han nacido o crecido en el contexto urbano; por lo tanto, sus imaginarios, vivencias, percepciones y expectativas son distintas de las de los jóvenes migrantes.

Para algunos jóvenes que nacieron o crecieron en Bogotá, ya sea porque su comunidad ha vivido en esta región desde tiempos inmemorables (v.gr. los muiscas $)^{4}$ o porque llegaron cuando eran niños, la ciudad es su territorio ancestral, el lugar de donde proviene la vida del ser humano y donde se conserva la memoria, la energía y el espíritu de sus antepasados. Por consiguiente, organizan pagamentos, círculos de la palabra y rituales en los sitios que consideran sagrados, como son el cerro de Monserrate, el cerro de Guadalupe y el jardín botánico, entre muchos otros.

Para estos jóvenes, la ciudad tiene un significado mucho más profundo que para los demás ciudadanos, puesto que no solo la perciben como el lugar que habitan y en donde desarrollan la mayoría de sus actividades cotidianas, sino también como un entorno que condiciona su existencia y su futuro en cuanto miembros de una comunidad ancestral; en consecuencia, se observa una relación conflictiva entre su imaginario y el imaginario de ciudad socialmente instituido. Un ejemplo fehaciente de ello es su relación con el agua: mientras que para la mayoría de habitantes de la ciudad el agua es un recurso o un servicio que funciona bajo las lógicas del mercado, para estos jóvenes de origen étnico es un ser que tiene vida y derechos en sí mismo. Desde esta perspectiva, los jóvenes indígenas buscan instituir nuevos imaginarios en torno a la ciudad y sus recursos naturales.

Por otra parte, los jóvenes que llegaron a Bogotá a una edad avanzada de la adolescencia, ya sea por desplazamiento o en busca de oportunidades laborales o educativas, convergen en que la ciudad es un lugar donde pueden estudiar, trabajar y relacionarse con nuevas personas. Uno de los principales motivos de su traslado a la capital es el imaginario de que esta ciudad, en comparación con otras, dispone de una mejor infraestructura, mejores universidades y más oportunidades para salir adelante. Esta representación ha sido construida a partir de dos fuentes: 1) los relatos de familiares o amigos cercanos que han estudiado o trabajado en Bogotá; y 2) las imágenes y mensajes transmitidos por los medios masivos de comunicación:

Me vine para Bogotá, uno, porque habían (sic) unos familiares acá y, dos, porque como ya tenemos televisión, mirábamos que Bogotá era una ciudad de oportunidades, sigue siendo y lo seguirá siendo; entonces, de una u otra forma, uno puede emplearse en lo que sea acá. [...] A partir de eso, uno como que dice: "voy a irme a trabajar", "voy a conocer Bogota”, "Bogotá es grande", "Bogotá tiene muchas cosas" (entrevista 4, hombre, 28 años).

Pese a lo anterior, no todos los imaginarios sociales frente a la ciudad (particularmente Bogotá) son positivos. En algunos casos, las personas mayores temen que los jóvenes, al salir del territorio, queden expuestos a situaciones de vulnerabilidad, inseguridad o violencia urbana; en otros, se teme que las nuevas generaciones se dejen atraer por los

4. Los muiscas han habitado la región conocida como el altiplano cundiboyacense desde hace aproximadamente 2700 años. El territorio del pueblo muisca "abarcaba las cuencas y valles del río Bogotá hasta Tena, el río Negro hasta Quetame, el Guavio hasta Gachalá, el Garagoa hasta Somondoco, el Chicamocha hasta Soatá y el río Suárez hasta Vélez”. En la actualidad, los descendientes directos de los muiscas viven en las localidades de Suba y Bosa, y en los municipios de Cota, Chía, Sesquilé y Soacha (Martínez Bocanegra, 2013). Extraído de: http://www.escritoresyperiodistas.com/Ejemplar8/muisca.html 
valores de la cultura urbana occidental y de esta manera se pierda la continuidad y la reproducción de los valores, creencias y costumbres ancestrales. Por esta razón, a algunos jóvenes les resulta difícil trasladarse hacia los centros urbanos y la mayoría salen de su resguardo con el compromiso de reportarse con cierta regularidad.

Si se retoma el enfoque de los imaginarios sociales, la anterior situación evidencia cómo estos orientan y condicionan los pensamientos, las decisiones y las acciones cotidianas de los individuos. De esta manera, se observa que el imaginario de ciudad como ambiente de oportunidades, da pábulo a que los jóvenes indígenas se trasladen a las grandes urbes en busca de un mejor futuro. En cambio, el imaginario negativo frente a la ciudad produce temores, dudas e incertidumbre tanto en los jóvenes que desean trasladarse hacia los centros urbanos como en sus familias.

Una vez instalados en la metrópoli, los hombres y mujeres jóvenes afrontan a veces situaciones de discriminación a causa de su origen étnico. Esta exclusión puede presentarse de varias maneras: algunos han experimentado discriminación racial debido a sus rasgos físicos, su forma de hablar y su modo de vestir; otros han sido objeto de discriminación debido a que sus rasgos físicos y apariencia personal no se adaptan al estereotipo de indígena instituido por el imaginario social dominante:

Hay un racismo óptico bastante grande: pensar que se es indígena porque uno debe ser morochito, bajito $\mathrm{y}$ de ciertos rasgos es promover algo similar a lo que pasó en la Alemania nazi. [...] Teniendo en cuenta eso, hay algunos que piensan que uno debe tener equis forma física para ser indígena, cuando esto es más una herencia histórico-cultural (entrevista 10, hombre, 30 años).

La discriminación racial junto con otras problemáticas como la escasez de recursos económicos, la lejanía con respecto al territorio de origen o la desigualdad cultural, genera lo que Aravena (2009) denomina una experiencia de la etnicidad negativa que "[...] se asocia con sentimientos de rencor, de rabia, de depresión, de subvaloración y de sufrimiento de parte de quien enfrenta su vida cotidiana desde una identidad que percibe como subvalorada y despreciada" (Aravena, 2009, p. 50). En este contexto, los jóvenes migrantes pueden ocultar su identidad étnica o reafirmarla mediante un proceso de resignificación socioimaginaria "que permite un reencuentro con la propia identidad a partir de una valorización de la misma, como imaginario social subalterno" (Aravena, 2009, p. 51).

Así pues, las personas jóvenes desarrollan procesos de resignificación socioimaginaria de la etnicidad que les permiten recuperar o reafirmar su identidad, creencias, valores y costumbres ancestrales en el espacio urbano. Este proceso se lleva a cabo mediante el encuentro y la comunicación constante con otros jóvenes indígenas, el fortalecimiento de los lazos familiares y la ejecución de ciertas actividades con las que rememoran su territorio de origen:

Yo tengo bastantes amigos y entonces vamos a caminar juntos a los cerros orientales -casi siempre vamos a caminar allá. Acá hay otra amiga con quien siempre vamos a Fusa, a una finca que ella tiene; yo voy allá a colaborarle, o sea, siempre estoy tratando de buscar -porque a uno le hace mucha falta- el campo, la armonía, la tierra, todas esas cosas (entrevista 9, hombre, 25 años).

Por último, los jóvenes indígenas coinciden en que la figura del cabildo es fundamental para la recuperación y preservación de su identidad en medio de la cultura urbana dominante. Para ellos, dicha entidad pública de carácter especial ha permitido que las personas de origen étnico tengan un lugar propio donde encontrarse para hacer sus rituales y prácticas tradicionales; además, dado que el cabildo está conformado por personas de todas las edades, este espacio facilita el diálogo intergeneracional y por ende, la transmisión oral de la cultura:

Nosotros hemos llevado todas nuestras costumbres a través del cabildo, una entidad que nos ayuda y nos protege. Y nosotros también tenemos que hacer parte y protegerlo, porque a través del cabildo nosotros hacemos talleres, asambleas, reuniones acerca de cómo está la comunidad (entrevista 3, hombre, 30 años).

\section{La política desde una perspectiva étnico-juvenil}

Para los jóvenes indígenas, la política es una actividad que consiste en planear y tomar decisiones que afectan el orden, la organización social 
y la convivencia en comunidad. En esa medida, relacionan esta actividad con el funcionamiento del cabildo, la defensa del territorio, el respeto a los derechos individuales y colectivos y la búsqueda de acuerdos en pro del bien común, entre otros aspectos.

Para mí la política es la organización, digamos, de todos los ideales y de todos los proyectos de la comunidad; organizarlos de tal manera que todos participemos en el rumbo de la comunidad (entrevista 9, hombre, 25 ańos).

Al relacionar la política con decisiones que afectan el orden, la organización social y la convivencia, los jóvenes sugieren que los asuntos políticos ocupan un lugar predominante en sus vidas y en su cotidianidad; en consecuencia, procuran estar informados y participar en reuniones, asambleas y movilizaciones sobre asuntos que conciernen a sus derechos, costumbres, cosmovisiones o formas de organización tradicional.

Cabe destacar que este imaginario social en torno a la política ha sido construido a partir de la trasmisión de conocimientos por parte de los adultos y de la participación activa de las nuevas generaciones en actividades y discusiones comunitarias; por lo tanto, el imaginario político contiene tanto elementos culturales emanados de los procesos de re-significación socioimaginaria de la etnicidad, como elementos propios de la subjetividad de las personas entrevistadas (Martínez Iglesias, 2013).

Por otra parte, las entrevistas individuales y el grupo focal permitieron identificar que los jóvenes tienen una imagen negativa frente a los políticos de profesión como alcaldes, congresistas, presidentes, etc., a quienes asocian con hechos de corrupción, autoritarismo, ineficiencia administrativa o incumplimiento de promesas electorales:

Realmente yo pensaría que la política en sí no es mala, sino que quienes llegan a ejercer ese tipo de cargos son las personas que no permiten que haya progreso, que se generen nuevas ideas, porque finalmente se manejan a su conveniencia; solo cumplen esos roles jerárquicos que no dejan de existir: "nosotros somos los que mandamos, somos los que oprimimos" y, finalmente, no dejan que la gente acceda a oportunidades (grupo focal, mujer, 20 ańos).

Asimismo, se da un imaginario negativo frente a ciertas instituciones como el Estado y los partidos políticos: por un lado, algunos jóvenes critican que el Estado, representado en el Gobierno nacional, no destine suficientes recursos para desarrollar políticas sociales, ignore las necesidades y reivindicaciones propias de los pueblos indígenas o favorezca intereses particulares; por otro, un pequeño grupo de jóvenes responsabiliza a los partidos políticos de dividir la población y de suscitar actos de violencia en algunas regiones del país, principalmente, en épocas preelectorales.

A pesar de la imagen negativa que los jóvenes indígenas tienen acerca de la clase política y de ciertas instituciones, la mayoría de ellos afirma estar de acuerdo con el modelo de democracia representativa. Ante preguntas como: "¿qué piensa de las elecciones?” O “¿alguna vez ha votado?”, se encontró que los jóvenes consideran el voto no solo como un derecho ciudadano, sino también como la manera más adecuada de tomar decisiones importantes y de elegir a los representantes de los diferentes sectores sociales. Sin embargo, les atribuyen a los procesos electorales grandes falencias derivadas de la compra de votos, el clientelismo, los fraudes y el hecho recurrente de candidatos que incumplen sus promesas una vez han sido elegidos. Esto ha reforzado en otro grupo el imaginario de que las elecciones son una mentira y que los políticos solo buscan obtener poder y dinero a costa de las necesidades de la comunidad:

Por medio de las elecciones se ve que los candidatos juegan con la necesidad de la gente y también con la falta de educación [...] Los políticos aprovechan eso, porque realmente son poquitos los que tienen un interés comunitario, como del bien común; la mayoría están ansiosos de poder, de seguir ascendiendo económicamente $\mathrm{y}$, desafortunadamente, las elecciones se han corrompido (entrevista 6, mujer, 25 años).

Hombres y mujeres jóvenes que han participado en procesos electorales revelan que han apoyado, principalmente, a candidatos indígenas de su mismo cabildo o pueblo étnico. Algunos de ellos lo han hecho porque se identifican culturalmente y políticamente con dichos candidatos; otros, en cambio, lo han hecho exclusivamente para acceder a los beneficios del certificado electoral: descuento del $10 \%$ en la matrícula de la universidad, media jornada de descanso compensatorio remunerado, entre otros. Frente a los candidatos de origen étnico, se identificó un punto de divergencia entre 
los participantes de este estudio, pues mientras algunos defendían la importancia de apoyarlos al considerar el mayor conocimiento que tienen de las problemáticas y necesidades de los pueblos indígenas (tanto en el territorio como en la ciudad), la gran mayoría sostuvo que dichos candidatos han adoptado los mismos vicios y comportamientos de la clase política tradicional:

Yo voto porque es importante participar. Acá pasa que uno vota por los candidatos indígenas porque supuestamente son conocidos y trabajan para los indígenas, es eso (entrevista 11, mujer, 23 años).

En términos de participación política, los indígenas que han entrado en ese método de representación han asumido los vicios y la corrupción de la democracia parlamentaria colombiana. [...] Y lo podemos ver ¿no? Digamos, personas que han ejercido cargos en el Estado y que ahora están en la cárcel, siendo indígenas (entrevista 10, hombre, 30 años).

Las discusiones llevadas a cabo a través del grupo focal permitieron constatar que la figura del cabildo es un referente predominante dentro del imaginario político de la población juvenil indígena. Los jóvenes asocian la entidad especial del cabildo con las ideas de autoridad, representación, justicia, autonomía y democracia. Asimismo, consideran que tienen un papel relevante dentro de dicha entidad: primero, porque -en la mayoría de comunidades- a partir de los catorce años de edad pueden participar activamente en la elección de los cabildantes (gobernador, alcalde mayor, alguaciles, tesorero, etc.); y, segundo, porque una vez cumplidos los dieciocho ańos pueden ser elegidos en cargos de autoridad. Sobre la base de lo anterior, los jóvenes conciben su participación en reuniones y demás actividades organizadas por el cabildo como una forma de prepararse para asumir responsabilidades políticas en el futuro. Entretanto, algunos han desarrollado iniciativas propias de organización juvenil como concejos de juventud, comités de juventud o cabildos indígenas universitarios, con el propósito de tratar asuntos referidos a becas, convenios educativos y diferentes problemáticas que los afectan.

Ahora bien, al explorar los sentidos y prácticas políticas alternativas de los jóvenes indígenas se encontró, por un lado, que para algunos el ejercicio de la política no se reduce a los mecanismos y espacios convencionales de participación (v.gr elecciones, partidos políticos, etc.), sino que también incluye actividades como reflexionar en el círculo de la palabra ${ }^{5}$, colaborar con la minga ${ }^{6} \mathrm{o}$ unirse a la guardia indígena ${ }^{7}$. Por otro lado, la mayoría de jóvenes respalda la movilización social, la cual es concebida como un medio válido y efectivo para exigir derechos y transformar la realidad presente. De este modo, hombres y mujeres jóvenes generan procesos de resignificación socioimaginaria de la política a partir de su cosmovisión e identidad étnica, lo que no solo implica un distanciamiento con respecto al imaginario de política socialmente instituido, sino también la configuración de nuevos intereses, actitudes y prácticas políticas.

Los mencionados procesos de resignificación socioimaginaria de la política también se reflejan en las reivindicaciones propias de la población juvenil indígena. Si bien los jóvenes apoyan mayoritariamente demandas sobre asuntos estructurales como la pobreza, el desempleo, la exclusión social, la distribución de la tierra, etc., también se observa una preocupación por asuntos relacionados con su cotidianidad, como el servicio militar obligatorio, el medio ambiente, el conflicto armado, los derechos de la mujer y la descolonización del pensamiento, entre otros. Igualmente, algunos jóvenes consideran que parte de sus reclamos políticos giran en torno a su concepción de territorio, que incluye el resguardo, el cabildo y los sitios sagrados. En su opinión, mientras los indígenas mantienen una relación cultural con el territorio y los recursos naturales que para ellos es un derecho ancestral, la racionalidad occidental concibe el suelo desde una perspectiva puramente mercantil y de explotación económica, lo que genera inconformidad

5. El círculo de la palabra es un espacio destinado para la tradición oral y el diálogo intercultural. Allí, un taita o sabedor muisca transmite a los asistentes información acerca del pensamiento, usos y costumbres de su pueblo. El algunas ocasiones, el círculo de la palabra es el entorno donde se toman decisiones colectivamente sobre asuntos o problemas que afectan a la comunidad (Sua Gua Gua, 2012).

6. En términos amplios, minga significa trabajo colectivo para un fin determinado que beneficia a toda la comunidad.

7. La guardia indígena es un colectivo cívico, compuesto por hombres y mujeres de todas edades, cuya función consiste en cuidar y defender la vida, el territorio y la autonomía de los pueblos indígenas en coordinación con las autoridades tradicionales y la comunidad. Guardia indígena (n. d.) Recuperado de http://www.cric-colombia.org/portal/guardia-indigena/ 
y conflictos en algunas zonas de la ciudad (y, por supuesto, del país):

Hay sitios sagrados, espiritual y energéticamente hablando, que están siendo insultados por el proyecto de mega-minería y la contaminación del agua, que es el elemento vital y más sagrado para los pueblos indígenas. [...] El río Tunjuelo, que baja del río Sumapaz, por donde según nuestra ley de origen llegó Bochica, está afectado hace más de 30 años por el parque minero-industrial en donde está Cemex y otras transnacionales; $y$ hasta el ejército nacional ha permitido que haya explotación de canteras inmensas con una huella ecológica inmensa en esa zona (entrevista 10, hombre, 30 años).

En síntesis, el surgimiento y la adopción de nuevas actitudes, prácticas y reivindicaciones políticas por parte de los jóvenes indígenas refleja que, al igual que otros sectores juveniles, estos sujetos están experimentando una dislocación frente a las formas convencionales de concebir y ejercer la política (Wilkinson, 2002). Así pues, los jóvenes indígenas han construido nuevas significaciones con respecto a la política haciendo confluir sus vivencias e intereses personales, por un lado, con las creencias, valores y costumbres tradicionales de su comunidad, por otro.

\section{A manera de conclusión}

Este estudio permitió evidenciar cómo la noción de juventud se erige e incorpora dentro del imaginario social instituido a partir de ciertos procesos de reconocimiento y legitimación de los jóvenes como grupo significativo, en el marco de unas condiciones sociohistóricas determinadas. Particularmente, la noción de juventud indígena es una construcción social reciente que ha surgido de modo relativo en algunas comunidades étnicas gracias a las nuevas formas de relacionamiento entre estas comunidades y las sociedades urbanas. Entre los fenómenos que han posibilitado dichas formas de relacionamiento y por ende, el surgimiento de la condición étnico-juvenil, se encuentran el acceso a la educación secundaria y universitaria, los procesos migratorios hacia los centros urbanos y la influencia de los medios masivos de comunicación.

A pesar de que la condición juvenil está determinada por los significados, itinerarios, papeles y características que le atribuye cada sociedad, se observa que los jóvenes indígenas devienen como sujetos de la imaginación radical en la medida en que recrean nuevas imágenes y significaciones sobre dicha condición con base en sus vivencias, percepciones y expectativas individuales y colectivas, en cuanto miembros de una comunidad ancestral. En consecuencia, los jóvenes de origen étnico se distancian del imaginario social de juventud instituido que de manera determinista define la condición juvenil por un margen de edad y unos rasgos psicobiológicos particulares, para instituirla como una etapa de aprendizaje, esto es, un estadio transitorio que todas las personas deben atravesar mientras adquieren la madurez, los conocimientos, las habilidades y las destrezas necesarias para asumir las responsabilidades de los mayores. Esto no significa que los jóvenes no tengan responsabilidades - de hecho, en cada etapa social los miembros de la comunidad deben asumir ciertas responsabilidades-, sino más bien, que sus estas son distintas: ayudar a los adultos en tareas cotidianas, trabajar la tierra, prepararse en sentido espiritual e intelectual para fortalecer los procesos organizativos y políticos de su comunidad, entre otras. Cabe destacar que el aprendizaje no se reduce a la educación formal, pues para los jóvenes indígenas los conocimientos también emanan del trabajo y del diálogo permanente con los adultos y ancianos de la comunidad. Adicionalmente, dentro del imaginario de los jóvenes indígenas, la juventud se caracteriza por la disponibilidad de tiempo para llevar a cabo actividades distintas al trabajo o el estudio: practicar deportes, salir a fiestas, etc.; por lo tanto, la condición juvenil se agota en la medida en que se asumen responsabilidades propias del mundo adulto y se reduce el tiempo libre destinado al esparcimiento, la diversión, el ocio y el deporte.

El imaginario que los jóvenes indígenas han construido en torno a la ciudad (particularmente la ciudad de Bogotá) varía según la forma como entraron en contacto con el espacio urbano. Por lo tanto, mientras los jóvenes que nacieron o crecieron en Bogotá mantienen un fuerte vínculo espiritual y cultural con la capital, los jóvenes migrantes la conciben primordialmente como un escenario de oportunidades. Mientras los primeros mantienen sus costumbres y continúan con sus rituales y pagamentos en los sitios que consideran sagrados, los segundos priorizan sus 
actividades educativas y laborales al tiempo que entran en contacto permanente con su familia y su territorio de origen. De esta manera, los jóvenes indígenas que viven en Bogotá han resignificado su identidad, sus formas de relacionamiento y el espacio simbólico que habitan (Hurtado, 2006). Ahora bien, ante el riesgo de perder la identidad étnica en virtud de la coacción de la cultura urbana dominante, los jóvenes mantienen un fuerte vínculo con el cabildo de su comunidad el cual es percibido como el espacio más importante para la preservación y reproducción de sus valores, creencias y costumbres ancestrales.

Dentro del imaginario de los jóvenes indígenas, la ciudad también es concebida como lugar de conflictos interculturales, pues muchos de ellos han enfrentado situaciones de discriminación a causa de su origen étnico. Ante dichos actos, los jóvenes generan múltiples procesos de resignificación de la etnicidad mediante el establecimiento de redes sociales y comunitarias, el contacto permanente con familiares y amigos indígenas y la recreación de ambientes y escenarios con los que rememoran su territorio de origen.

En cuanto al imaginario político de los jóvenes indígenas, se observa que la política es entendida de modo general como la planeación y la toma de decisiones que afectan el orden, la organización social y la convivencia; en cambio, los políticos son percibidos como aquellas personas que solo buscan poder y dinero valiéndose de promesas electorales que nunca cumplen. Asimismo, los jóvenes entrevistados no manifiestan ningún interés de aspirar a un cargo de representación dentro del Estado; sin embargo, consideran que la política está presente y afecta muchas de sus actividades cotidianas y, por ende, procuran estar informados y participar en actividades, reuniones o asambleas de su cabildo o comunidad.

Las prácticas políticas alternativas de la población juvenil indígena permiten constatar un distanciamiento con respecto al imaginario político socialmente instituido. En este orden de ideas, los jóvenes consideran que la participación democrática no se reduce a los mecanismos establecidos constitucionalmente para ello, sino que también abarca ciertos espacios de encuentro comunitario como el círculo de la palabra o la minga. Por otra parte, sus reivindicaciones políticas denotan que los jóvenes indígenas han asumido nuevos intereses y compromisos políticos relacionados con su cotidianidad y su cosmovisión en el contexto urbano.

\section{Bibliografía}

- ACOSTA, Fabián; GALINDO RAMÍREZ, Liliana y CUBIDES MARTÍNEZ, Juliana (2011). Sentidos y prácticas políticas en el mundo juvenil universitario. Bogotá: Universidad Nacional de Colombia. Facultad de Derecho, Ciencias Políticas y Sociales. Vicedecanatura de Investigación y Extensión.

- AGUDELO, Pedro (2011). (Des)hilvanar el sentido/los juegos de Penélope. Una revisión del concepto imaginario y sus implicaciones sociales. En: Uni-pluri/versidad, 11(3). pp. 93-110.

- ARANGO, Luz Gabriela (2006). Jóvenes en la universidad. Género, clase e identidad profesional. Bogotá: Siglo del Hombre Editores.

- ARAVENA, Andrea (2009). La resignificación imaginario-social de la etnicidad como componente de participación ciudadana y política en las y los jóvenes en la ciudad de Santiago de Chile. En: Revista Observatorio de Juventud, 22. pp. 47-58.

- ARAVENA, Andrea, y ÁLVAREZ, Carolina (2012). Juventud, migración y discriminación en el Chile contemporáneo. En: Última década, 20(36). pp. 127-140.

- CASTORIADIS, Cornelius (1989). La institución imaginaria de la sociedad II. Barcelona: Tusquets editores.

- CARDONA, Rokael (1999). Desafíos de una política de juventud rural indígena en Guatemala. En: Boletín XIII, Jóvenes, formación y empleo, Cinterfor/OIT, Año 1, No. 13. 
- CASTRO POZO, Maritza Urteaga (2008a). Lo juvenil en lo étnico. Migración juvenil indígena en la sociedad contemporánea mexicana. En: Revista ponto-e-vírgula 4. pp. 261 - 275.

- CASTRO POZO, Maritza Urteaga (2008b). Jóvenes e indios en el México contemporáneo. En: Revista Latinoamericana de Ciencias Sociales, Niñez y Juventud, 6 (2). pp. 667-708.

- CUBIDES MARTÍNEZ, Juliana (2011). Jóvenes y política ¿de objetos a sujetos de política? En ACOSTA, Fabian, GALINDO RAMÍREZ, Liliana y CUBIDES MARTÍNEZ, Juliana. Sentidos y prácticas politicas en el mundo juvenil universitario. Bogotá: Universidad Nacional de Colombia. Facultad de Derecho, Ciencias Políticas y Sociales. Vicedecanatura de Investigación y Extensión.

- DEL POPOLO, Fabiana y RIBOTTA, Bruno (2011). Migración de Jóvenes Indígenas en América Latina. En DEL POPOLO, F. (coord.). Pueblos Indígenas y Afrodescendientes en América Latina: Dinámicas Poblacionales Diversas y Desafíos Comunes. Río de Janeiro: ALAP - UNFPA.

- FEIXA, Carles y GONZÁLEZ, Yanko (2006). Territorios baldíos: identidades juveniles indígenas y rurales en América Latina. En: Papers, 79. pp. 171-193.

- FRESSARD, Oliver (2006). El imaginario social o la potencia de inventar de los pueblos. En: Revista Trasversales, 2. pp. 58-63.

- GALINDO RAMÍREZ, Liliana (2012). Política, juventud e Internet: transformaciones y perspectivas de comprensión en América Latina. En: Utopía y Praxis Latinoamericana, Abril-Junio. pp. 11-30.

- GALLART NOCETTI, María Antonieta y HENRÍQUEZ BREMER, Cristina (2006). Indígenas y educación superior: algunas reflexiones. En: Universidades, julio-diciembre. pp. 27-37.

- HURTADO, René (2007). La configuración de significaciones imaginarias de deseo en jóvenes de la ciudad de Popayán (2003-2007). Tesis Doctoral, Universidad de Manizales, CINDE, Colombia.

- HURTADO, René (2006). Jóvenes e imaginarios: la perspectiva instituida y la configuración de lo instituyente. En: Congresso Brasileiro de Ciencias da Comunicao 29, Brasilia. Anais. Sáo Paulo: Intercom [CD-ROM].

- MAYORGA, Martha Lilia (2008). Jóvenes indígenas universitarios en Colombia. En: PÉREZ RUIZ, Maya Lorena (Coord.). Jóvenes indígenas y globalización en América Latina. México: INAH, Colección Científica.

- ORTELLI, Paola y SARTORELLO, Claudio (2011). Jóvenes universitarios y conflicto intercultural. Estudiantes indígenas y mestizos en San Cristóbal de Las Casas, Chiapas. En: Perfiles Educativos 33. pp. 115-128.

- PÉREZ RUIZ, Maya Lorena (2008). Jóvenes indígenas y globalización en América Latina. México: INAH, Colección Científica.

- PINTOS, José Luis (2001). Los imaginarios sociales del delito. La construcción social del delito por medio de las películas (1930-1999). En: AA.VV. Política criminal, derechos humanos y sistemas jurídicos en el siglo XXI. Homenaje al Dr. Pedro David, Buenos Aires, Depalma.

- UNDA LARA, René y MUÑOZ, Germán (2011). La condición juvenil indígena: Eelementos iniciales para su construcción conceptual. En: Ultima Década 34, junio. pp. 33-50.

- WILKINSON, Helen (2002). Hijos de la libertad ¿̨urge una nueva ética de la responsabilidad individual y social? En: BECK, Ulrich (ed.). Hijos de la Libertad. México: Fondo de Cultura Económica.

- ZAPATA CARDONA, Andrés y HOYOS AGUDELO, Mauricio (2005). ¿Existe una condición de juventud indígena? En: Nómadas, 23. pp. 28-37.

\section{Webgrafía}

- ALCALDÍA MAYOR DE BOGOTÁ (2011). Politica Pública Distrital para el reconocimiento, garantía, protección y restablecimiento de derechos de los pueblos indigenas. Bogotá D.C., Colombia. Recuperado de http:// www.integracionsocial.gov.co/anexos/documentos/polpublicas/pol\%C3\%ACtica\%20ind\%C3\%ACgena.pdf. 
- FALLA, Ricardo (2008). Migración retornada y juventud indígena (Zacualpa, Guatemala) En: Revista Encuentro, Migrantes transformando Centroamérica 80.pp.108-126. Recuperado de http:/www.enlaceacademico.org/ uploads/media/encuentro80.pdf.

- GUZMÁN ROCHA, Martha (2005). El imaginario socio-político del movimiento zapatista. En: El Cotidiano 20(131). pp. 72-77. Recuperado de http://www.redalyc.org/articulo.oa?id=32513109.

- MARTÍNEZ IGLESIAS, Jaime (2013). ¿Qué son los imaginarios? Recuperado de www.escenaytecnica.cl/ articulos/item/download/10.

- SUA GUA GUA (2012/02/01). ¿Qué es un círculo de la palabra con los abuelos muiscas? [Archivo de video]. Recuperado de http://www.youtube.com/watch?v=LdonLK2laB8). 